\title{
Guía de estrategias activas de enseñanza-aprendizaje para desarrollar competencias transversales en alumnos auditores
}

\section{Guide of active teaching-learning strategies to develop transverse competences in audit students}

\author{
Cristian Blanco Alfaro' ${ }^{1}$, Patricia Cortés Iturrieta ${ }^{2}$, Alberto Hernández Venegas ${ }^{3}$
}

\section{RESUMEN}

El paradigma educativo durante este último siglo ha cambiado considerablemente, se ha transitado de un modelo centrado en la enseñanza, a un modelo centrado en el aprendizaje. Autores como Tobón (2005), enfatizan la importancia de potenciar tanto el desarrollo de competencias técnicas como transversales a la hora de lograr la conformación del ser humano holista que la sociedad actual demanda.

Es bajo este contexto, que surge el presente proyecto, el cual tiene como finalidad potenciar el desarrollo de las competencias transversales de Trabajo en Equipo, Autonomía, Lectura Comprensiva y Razonamiento Lógico Matemático, en los estudiantes del VIII nivel de la Carrera de Auditoría de la Universidad de La Serena, valiéndose para esto, de la elaboración e implementación de una guía de estrategias activas de enseñanza-aprendizaje. Pues la valoración del desarrollo de estas competencias en términos medios por parte de los alumnos y de los agentes estratégicos vinculados con estos, constituye uno de los focos problemáticos presentes.

La metodología de este proyecto, se sustenta en un paradigma socio-crítico, con un enfoque cualitativo y un diseño metodológico de investigación-acción, siendo la aplicación de la entrevista, el focus groups y la encuesta, bases tanto para el diagnóstico del estudio, como para evaluar el impacto de la implementación de la guía.

Resultado de esta implementación en los estudiantes a través de las asignaturas del VIII nivel, se evidencia una mejora en el desarrollo de las competencias transversales precisadas en el perfil de egreso de esta carrera. Destacándose, el desarrollo de las competencias de Trabajo en Equipo y Autonomía, contando estas con una aprobación de más del $60 \%$, y observándose mejoras en la Lectura Comprensiva y el Razonamiento Lógico Matemático, superando el $50 \%$ más uno.

Palabras Clave: Autonomía, competencia transversal, estrategia activa de enseñanza aprendizaje, lectura comprensiva, razonamiento lógico matemático, trabajo en equipo.

Recepción: 22/05/2018. Aprobación: 20/12 /2018.

1 Departamento de Ciencias Económicas y Empresariales, Facultad de Ciencias Sociales y Económicas, Universidad de La Serena, Chile, cblanco@userena.cl

2 Departamento de Ciencias Económicas y Empresariales, Facultad de Ciencias Sociales y Económicas, Universidad de La Serena, Chile, pcortes@userena.cl

3 Departamento de Ciencias Económicas y Empresariales, Facultad de Ciencias Sociales y Económicas, Universidad de La Serena, Chile, ahernandez@userena.cl 


\begin{abstract}
The educational paradigm during this last century has changed considerably, it has moved from a model centered on teaching, to a model centered on learning. Authors such as Tobón (2005), emphasize the importance of enhancing both the development of technical skills and cross-cutting when it comes to achieving the conformation of the holistic human being that today's society demands.

It is in this context that the present project arises, which aims to promote the development of the transversal competences of Teamwork, Autonomy, Comprehensive Reading and Mathematical Logical Reasoning, in the students of the 8th level of the Audit Course of the University of La Serena, using this, the development and implementation of a guide to active teaching-learning strategies. For the assessment of the development of these competences in medium terms by students and strategic agents linked to these, is one of the problematic foci present.

The methodology of this project is based on a socio-critical paradigm, with a qualitative approach and a methodological design of action research, with the application of the interview, the focus groups and the survey, bases for the diagnosis of the study, as to evaluate the impact of the implementation of the guide.

The result of this implementation in the students through the subjects of the VIII level, there is evidence of an improvement in the development of the transversal competences specified in the graduation profile of this Degree. Standing out is the development of Teamwork and Autonomy skills, counting these with an approval of more than $60 \%$, and improvements in Comprehensive Reading and Mathematical Logic Reasoning are observed, exceeding 50\% plus one.
\end{abstract}

Keywords: Autonomy, transversal competence, active teaching-learning strategy, comprehensive reading, mathematical logical reasoning, teamwork.

\title{
INTRODUCCIÓN
}

Producto del paradigma constructivista y su nueva forma de enfocar la educación, los modelos paradigmáticos antiguos comienzan a mostrar su caducidad, poco a poco la forma de entender la vida y el mundo comienza a dar un vuelco en $360^{\circ}$, afectando a cada una de las esferas de la sociedad, donde la educación no deja de estar ajena a estas transformaciones, enfrentándose ante una nueva panorámica, donde los modelos conductistas y el proceso educativo centrado en la enseñanza y en los resultados, comienza a dar paso a un nuevo modelo, cuyo actor central pasa a ser el estudiante y donde el proceso de aprendizaje se transforma en su principal finalidad. Es así, que producto de estos cambios paradigmáticos y centrando el foco de atención en lograr un aprendizaje significativo en el alumno, el cual le permita desenvolverse adecuadamente en la sociedad, emerge el concepto de competencias. Distintas son las definiciones que se plantean frente a este término, pero todas ellas concuerdan en definirlas según Tobón (2007), como un conjunto de conocimientos, habilidades, destrezas, valores y actitudes, con un compromiso ético, que son desarrolladas por el ser humano y que facilitan su manejo óptimo en el sistema social. Es entre esta gama de competencias que surgen las así llamadas competencias transversales, las cuales pueden ser definidas según el Proyecto Tuning A.L (2007), como aquel conjunto de conocimientos, habilidades, destrezas, actitudes y valores, de carácter genérico, necesarias para cualquier graduado universitario y que sustentan su accionar en la conjunción de saberes orientados a 
servir de base para el desarrollo de las demás competencias. Es así, que las competencias transversales parecen emerger como respuesta a una sociedad cambiante.

Ante esto, las universidades actualmente tienen un gran desafío, pues no basta solo con destacar la importancia que adquieren las competencias transversales, sino también deben resolver el problema de cómo aplicarlas al interior de sus mallas curriculares. Pues la formación de competencias genéricas, requiere la utilización de estrategias de enseñanza-aprendizaje que fomenten la globalidad, el aprendizaje interdisciplinario, el rol activo del estudiante y la integración de saberes. Es de esta manera, que surgen las estrategias activas de enseñanza-aprendizaje, las cuales buscan generar cambios significativos en el aula de clase, pretendiendo dejar de lado la educación tradicional, de tal forma que se modifique el pensamiento de que el estudiante es una caja vacía que necesita ser llenada o alimentada con el conocimiento impartido por el profesor, quien es el que posee la verdad absoluta.

Según Serna (2013), las metodologías activas son los procedimientos que indican que para realizar un aprendizaje significativo, el alumno debe ser el protagonista de su propio aprendizaje, mientras el docente asume el rol de facilitador de este proceso. Para atenuar el desarrollo de las competencias, el docente propone a sus alumnos actividades de clases, tareas personales o grupales, que desarrollen una reflexión crítica, un pensamiento creativo, y una comunicación efectiva en el proceso de aprendizaje. Esto genera una mayor comprensión, motivación y participación del estudiante, ayudándolo a significar la información, por medio de estrategias donde la entrega de contenidos debe estar mediada por una mirada contextualizada de lo entregado acorde a su propia experiencia, pudiendo potenciar procesos cognitivos de distinta índole, instando así un afán crítico y resolutivo, propiciando una aplicación práctica de los contenidos e inculcando aspectos actitudinales.

En Chile, las Universidades pertenecientes al Consejo de Rectores de Universidades Chilenas, (CRUCH), no siendo ajenas a la nueva realidad, han promovido desde principios del siglo XXI cambios radicales en la forma de llevar a cabo los procesos de enseñanza.-aprendizaje, instando a sus instituciones pertenecientes a adoptar los nuevos modelos imperantes. Un ejemplo de esto es el caso de la Universidad de La Serena, la cual ha comenzado a transitar de un modelo basado en objetivos a un modelo basado en competencias, transformándose la instauración de este nuevo modelo en una de sus principales prioridades. Tomando como base las premisas declaradas en este nuevo modelo, es que las diversas carreras de esta universidad, han comenzado a acogerse al plan de renovación curricular propuesto por esta casa de estudios, donde una de las primeras carreras a adherirse a este nuevo plan es la Carrera de Auditoría, implementándolo a partir del año 2014, focalizando su accionar en lograr concretar el tan anhelado currículum renovado basado en competencias. De allí que esta carrera se transforme en el principal foco de atención de este proyecto de innovación educativa, donde por medio de un diagnóstico realizado, a la luz de la documentación propia de la carrera y desde la óptica de los principales agentes involucrados en la misma, evidencia una problemática focalizada en la formación de su alumnado, específicamente en el desarrollo de las competencias transversales en sus estudiantes de VIII nivel, quienes están próximos a egresar y quienes manifiestan ciertos vacíos en el desarrollo de estas competencias de base, asentándose así, un problema que viene de la raíz misma de su formación, donde el uso exclusivo de estrategias tradicionales de enseñanza-aprendizaje, generan limitaciones para el desarrollo de estas competencias. Tomando como base lo anterior entonces, se propone como 
objetivo general de este proyecto: Diseñar e implementar una guía de estrategias activas de enseñanza-aprendizaje para el desarrollo de competencias transversales en los alumnos que cursan las asignaturas del VIII nivel de la Carrera de Auditoría de la Universidad de La Serena. Sobre la base de esto mismo, se plantean también los siguientes objetivos específicos: a).- Identificar las competencias transversales declaradas en los programas de clases de las asignaturas del VIII nivel de la Carrera de Auditoría, b).- Analizar cómo repercuten las estrategias de enseñanza-aprendizaje aplicadas en las asignaturas del VIII nivel en el desarrollo de competencias transversales en sus alumnos, c).- Elaborar una propuesta de estrategias activas de enseñanza-aprendizaje para el desarrollo de competencias transversales en sus estudiantes, d).- Implementar la propuesta de estrategias activas de enseñanza-aprendizaje en las asignaturas del VIII nivel y e).- Evaluar la propuesta de estrategias activas de enseñanza-aprendizaje aplicada en las asignaturas del VIII nivel para el desarrollo de competencias transversales en sus alumnos.

Para el desarrollo de este proyecto de Innovación, y una vez visualizada la problemática de estudio, se propone una estructura basada en tres apéndices: El primero, denominado metodología, el segundo de ellos, denominado resultados, y el último, centrado en discusiones y conclusiones.

\section{METODOLOGIA, MATERIALES Y METODOS}

El presente estudio, se enmarca dentro de lo que se conoce como paradigma socio-crítico de investigación. Dicho paradigma, devela el traslado de la tarea del investigador al análisis de las transformaciones sociales y al fortalecimiento de respuestas de los problemas derivados de estas misma. Se caracteriza también por un enfoque cualitativo, buscando dar respuesta a una problemática de aquellos aspectos impalpables del comportamiento.

Por otra parte, el diseño de investigación-acción utilizado, considera técnicas e instrumentos tales como las siguientes: a).- Encuesta diagnóstico a los alumnos del VIII nivel año 2017, (27 estudiantes), b).- entrevista semiestructurada a informantes claves (Directora de Carrera y profesores de VIII nivel), c).- focus groups a egresados (año 2016), d).- encuestas de satisfacción a los alumnos del VIII nivel año 2017 (31 alumnos), encuesta de satisfacción docentes de VIII nivel (3 docentes) y f).- focus groups del impacto de la propuesta (alumnos y docentes).

\section{RESULTADOS}

A continuación se presentan los resultados, ordenados de acuerdo a sus objetivos específicos:

a).- Objetivo específico $\mathrm{N}^{\circ} 1$ : Identificar las competencias transversales declaradas en los programas de clases de las asignaturas del VIII nivel de la Carrera de Auditoría. La Carrera de Auditoría de la ULS, a partir del año 2014 se somete a un proceso de renovación curricular, respondiendo de esta manera a las exigencias de un nuevo Modelo Educativo, modelo centrado en la formación en competencias, donde producto de esto mismo, se generan cambios considerables en dicha carrera y en sus programas de clases, elaborándose así, una matriz de consistencia sobre la base de su perfil de egreso, llevando a tributar sus programas de asignaturas a esta matriz y a las competencias declaradas. De esta manera, y recurriendo a los tres programas de asignatura 
del VIII nivel, se establece la siguiente asociación:

Cuadro N$^{\circ}$ 1: COMPETENCIAS TRANSVERSALES Y ASIGNATURAS DEL VIII NIVEL.

\begin{tabular}{|l|l|}
\hline \multicolumn{1}{|c|}{ Asignatura } & \multicolumn{1}{c|}{ Competencia asociada } \\
\hline Proceso de Titulación II. & $\begin{array}{l}\text { Trabajo en equipo, liderazgo, autonomía e iniciativa personal y lec- } \\
\text { tura comprensiva. }\end{array}$ \\
\hline Taller de Contabilidad. & $\begin{array}{l}\text { Trabajo en equipo, liderazgo, autonomía e iniciativa personal, lec- } \\
\text { tura comprensiva, razonamiento lógico matemático y adaptación } \\
\text { al cambio. }\end{array}$ \\
\hline Taller de Auditoría. & $\begin{array}{l}\text { Trabajo en equipo, liderazgo, autonomía e iniciativa personal, lec- } \\
\text { tura comprensiva, razonamiento lógico matemático y adaptación } \\
\text { al cambio. }\end{array}$ \\
\hline
\end{tabular}

Fuente: Elaboración propia.

b).- Objetivo específico $\mathrm{N}^{\circ} 2$ : Analizar cómo repercuten las estrategias de enseñanza-aprendizaje aplicadas en las asignaturas del VIII nivel de la Carrera de Auditoría en el desarrollo de competencias transversales en sus alumnos. A través del último informe de acreditación de la Carrera de Auditoría, pueden detectarse una serie de aspectos necesarios a mejorar relacionados con el desarrollo de las competencias transversales en sus estudiantes, evidenciándose esto, por medio de los principales empleadores convocados por la carrera, quienes dan cuenta de algunos déficits en el desarrollo de este tipo competencias. Este hecho es corroborado con los resultados de los informes de práctica de los 55 alumnos egresados el año 2016, donde puede evidenciarse lo siguiente: De 7 competencias transversales consideradas, 35 alumnos fueron evaluados en términos medios (medianamente logrado) en función de la competencia de Trabajo en Equipo, 30 discentes, fueron evaluados en términos medios en función de la competencia de Lectura Comprensiva, 25 alumnos, fueron evaluados en estos mismos términos, en relación con la competencia de Manejo Computacional y 40 estudiantes, fueron evaluados de esta misma manera, en función de la competencia de Razonamiento Lógico Matemático. Por otra parte, un total de 21 estudiantes, fueron evaluados en términos negativos al considerar la competencia de Autonomía e Iniciativa Personal y 45 discentes, fueron evaluados positivamente en relación con la competencia de Vocación de Servicio. Lo anterior, corrobora un problema en el desarrollo de las competencias transversales en los estudiantes, hecho que se constata con las percepciones emitidas por la Directora de esta Carrera a través de una entrevista realizada para con ella, la cual entrega además razones que subyacen a este problema, señalando lo siguiente: "Lo indicado en los diversos informes emanados, sin duda es una realidad y entre las principales razones de esta evaluación, se encuentra el excesivo uso de estrategias tradicionales de enseñanza-aprendizaje por parte de los docentes, traducido esto principalmente en la clase magistral” (Directora, Entrevista $\mathrm{N}^{\circ} 1$ ).

Otro aspecto importante a destacar también, es lo señalado por los alumnos egresados de la generación 2016, quienes señalan que el uso excesivo de estas estrategias coarta la participación al interior del aula e impide construir por si mismos el conocimiento. Así lo señala uno de estos estudiantes: "En buena parte de mis asignaturas siempre fue lo mismo, diapositivas tras diapositivas, donde la participación en el aula, se limitaba a preguntar dudas" (Alumna, Focus Groups N¹). 
A lo anterior se le suma además, la opinión generalizada por parte de los tres académicos del VIII nivel, quienes señalan mediante una serie de entrevistas semiestructuradas (2017), que la técnica más utilizada por todos los docentes de la carrera, recae en la clase expositiva.

Como se puede apreciar, las repercusiones que trae consigo el monopolio de estrategias tradicionales de enseñanza aprendizaje en la Carrera de Auditoría, son variadas, irradiándose esto también a las nuevas generaciones, siendo un claro ejemplo de esto, lo que sucede con los alumnos que actualmente se encuentran cursando el VIII nivel de la Carrera de Auditoría (año 2017), donde producto de un diagnóstico que se lleva acabo, se puede constatar, que la competencia de Trabajo en Equipo es evaluada en términos medios respecto de su desarrollo, destacándose un $54 \%$ de los discentes, que precisan como medianamente logrado el contribuir a fomentar la participación activa de los miembros del grupo en los diálogos y discusiones considerando ideas propias y o experiencias, y un 55\% de ellos, que precisan de esta misma manera, el escuchar activamente las opiniones al interior del grupo y con el intergrupo. Lo señalado anteriormente, puede verse reflejado a través del siguiente gráfico:

\section{GRÁFICO Nº1: EVALUANDO MI DESARROLLO DE LA COMPETENCIA TRANSVERSAL DE TRABAJO EN EQUIPO.}

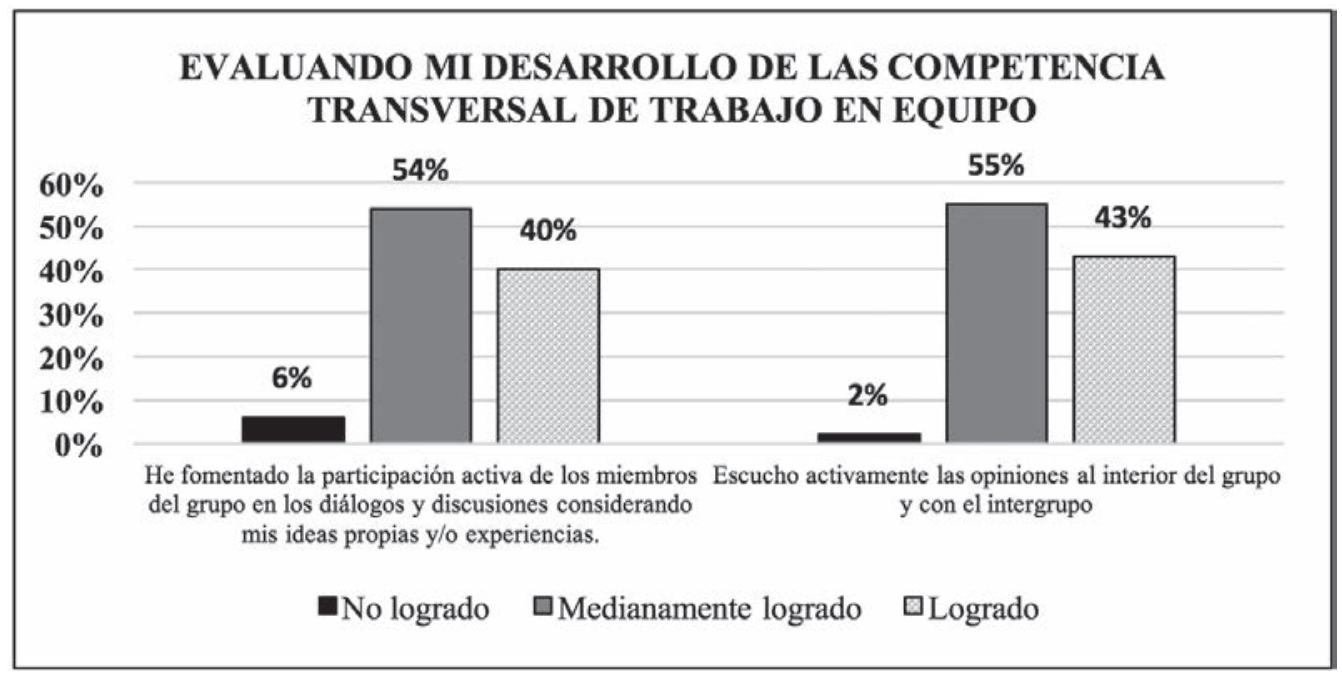

Fuente: Elaboración propia.

Respecto a la competencia de Autonomía e Iniciativa Personal, a diferencia de lo anterior, esta puede ser más bien evaluada en términos negativos en función de su desarrollo, destacándose un 53\% de los estudiantes, que precisan como no logrado el aportar en más de alguna ocasión con información relevante y actualizada a los desafíos que debe enfrentar el equipo, y un $67 \%$ de ellos, que indican en estos mismos términos, el proponer soluciones ante diversos problemas presentados. Estos porcentajes pueden ser expresados por medio del siguiente gráfico: 


\section{GRÁFICO N²: EVALUANDO MI DESARROLLO DE LA COMPETENCIA TRANSVERSAL DE AUTONOMÍA E INICIATIVA PERSONAL.}

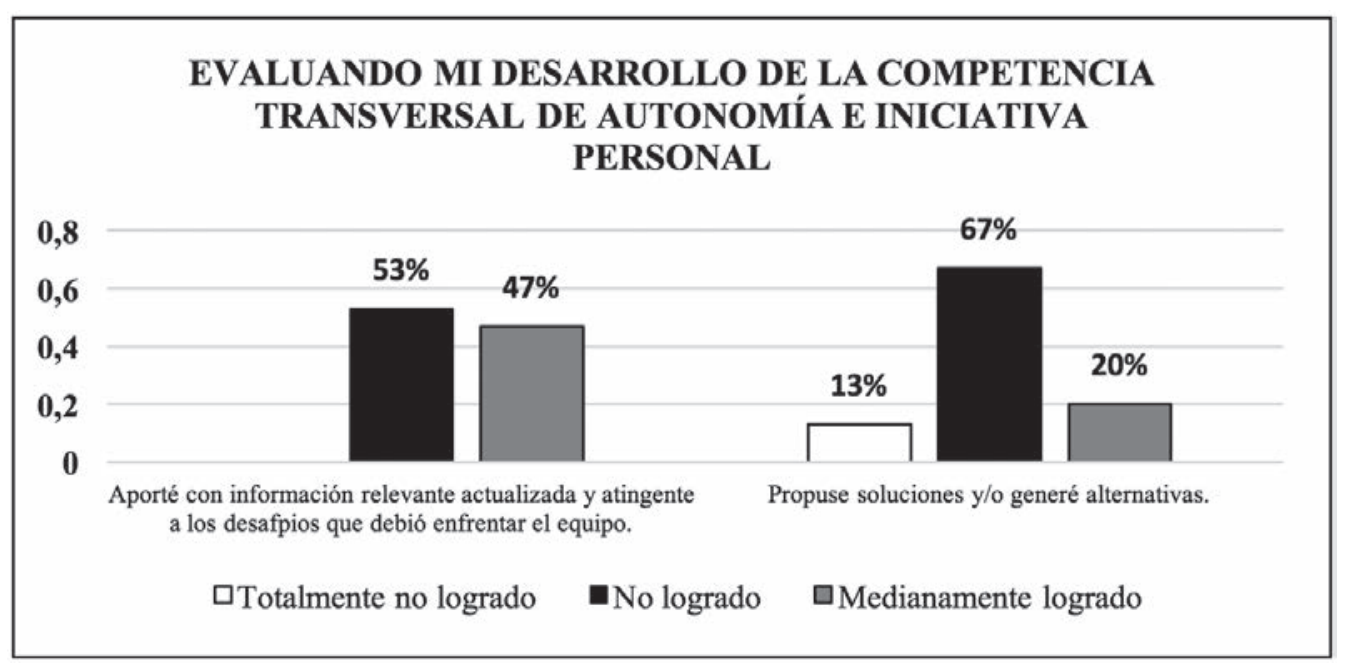

Fuente: Elaboración propia.

Por otra lado, en relación al desarrollo de la competencia de Lectura Comprensiva, es posible señalar, que esta también es evaluada mayoritariamente de forma negativa, donde un $57 \%$ de los discentes, señalan como no logrado el analizar y comprender los textos para interpretar proponer y argumentar, y un 67\%, evalúa como no logrado el analizar y relacionar los textos con la realidad.

Estos datos quedan reflejados de la siguiente manera:

GRÁFICO N³: EVALUANDO MI DESARROLLO DE LA COMPETENCIA TRANSVERSAL DE LECTURA COMPRENSIVA.

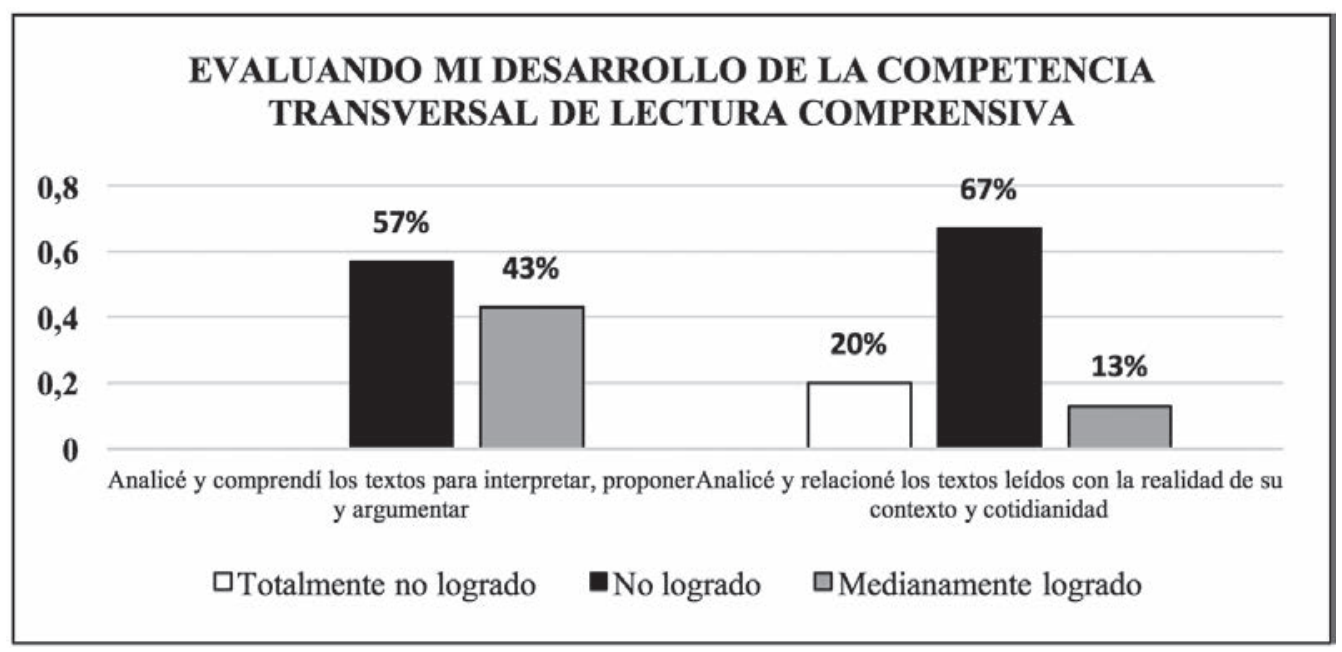

Fuente: Elaboración propia. 
Resultados similares arroja la competencia de Razonamiento Lógico Matemático, la cual es evaluada en términos medios a negativo respecto a su desarrollo, donde un $64 \%$ de los alumnos, señalan como medianamente logrado valorar el lenguaje contable como un instrumento útil para presentar, comunicar y resolver problemas de la vida diaria y un $60 \%$ de ellos, señalan como no logrado el demostrar facilidad al resolver una situación de la vida real mediante ecuaciones.

Esta información puede verse reflejada por medio del siguiente gráfico:

\section{GRÁFICO N4: EVALUANDO MÍ DESARROLLO DE LA COMPETENCIA TRANSVERSAL DE RAZONAMIENTO LÓGICO MATEMÁTICO.}

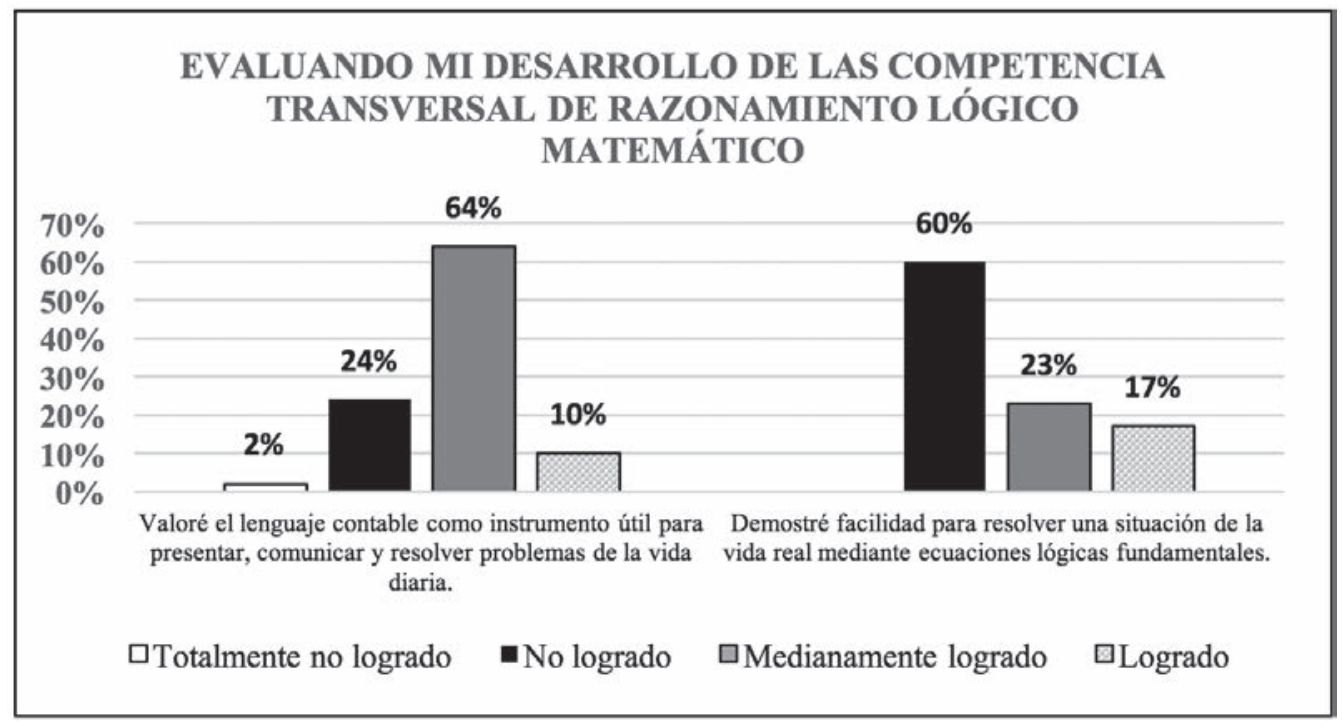

Fuente: Elaboración propia.

c).- Objetivo específico $\mathrm{N}^{\circ}$ : Elaborar una propuesta de estrategias activas de enseñanza-aprendizaje en las asignaturas del VIII nivel de la Carrera de Auditoría para el desarrollo de competencias transversales en sus alumnos.

El poder constatar el principal foco problemático de este proyecto de innovación sobre la base del diagnóstico precisado, lleva a generar la presente propuesta de innovación educativa, la cual en este caso, se orienta a una guía de estrategias activas de enseñanza-aprendizaje para el desarrollo de las competencias transversales en los estudiantes que cursan el VIII de la Carrera de Auditoría. Para lograr este cometido y respondiendo al objetivo específico evidenciado, en primer lugar, se procede a una revisión detallada de los programas de clases de las tres asignaturas de este último nivel, analizando las competencias transversales para con ellas tributadas. Como complemento a lo anterior, posteriormente se lleva a cabo un claustro académico con el Consejo de Escuela de la Carrera de Auditoría, orientándose este a analizar los programas de clases respectivos, las competencias transversales tributadas para con ellos, y una serie de estrategias activas de enseñanza-aprendizaje, buscando determinar así, las técnicas didácticas más acordes que ayuden al desarrollo de estas competencias. Resultado de este claustro, se logra establecer 
un primer documento en borrador, el que posteriormente en una segunda etapa, denominada diseñando la guía de estrategias activas de enseñanza-aprendizaje, es analizada por los investigadores a cargo del proyecto, elaborándose así una matriz de consistencia, la cual permite levantar la propuesta reflejada en la guía.

d).- Objetivo específico $\mathrm{N}^{\circ} 4$ : Implementar la propuesta de estrategias activas de enseñanzaaprendizaje en las asignaturas del VIII nivel de la Carrera de Auditoría para el desarrollo de competencias transversales en sus alumnos. Una vez realizada la capacitación a los docentes, se está en condiciones de implementar la guía en los alumnos, tomando en cuenta para esto, una aplicación paralela en las tres asignaturas consideradas y abordando la primera unidad de cada una de estas, todo esto con el fin de fomentar y reforzar en los estudiantes el desarrollo de competencias transversales por medio de las estrategias activas de enseñanza-aprendizaje entregadas. Es así, que para la asignatura de Proceso de Titulación II y haciendo uso de las técnicas didácticas de Trabajo Colaborativo y Portafolio de Trabajo a la hora de potenciar tanto el desarrollo de las competencias transversales de Autonomía e Iniciativa Personal, Trabajo en Equipo y Lectura Comprensiva, así como el logro del aprendizaje esperado de la unidad, se procede a desarrollar con los alumnos dos tareas específicas, donde mientras la primera está orientada a indagar en las técnicas de investigación científica, la segunda, tiene como finalidad, la elaboración de instrumentos de investigación. Ambas tareas son evaluadas por medio de rúbricas.

Para la asignatura de Taller de Contabilidad en cambio, se procede a trabajar sobre la base de las técnicas de Aprendizaje Basado en Problemas (ABP) y Portafolio de Trabajo, donde por medio de tres tareas realizadas y buscando potenciar las competencias transversales de Trabajo en Equipo, Autonomía e Iniciativa Personal, Lectura Comprensiva y Razonamiento Lógico Matemático, así como el aprendizaje esperado de la unidad, los alumnos resuelven problemas propio del área de la contabilidad, primero identificando los errores de los estados de cuenta de una empresa, posteriormente resolviendo dichos errores y por último, emitiendo un informe preliminar de ajuste de cierre, siendo evaluados estos por medios de rúbricas.

Por último, para la asignatura de Taller de Auditoría, y buscando potenciar tanto las competencias transversales de Trabajo en Equipo, Autonomía e Iniciativa Personal, Lectura Comprensiva y Razonamiento Lógico Matemático, así como el logro del aprendizaje esperado, se trabaja sobre la base de la técnica de Estudio de Casos y Portafolio de Trabajo, donde los estudiantes por medio de las dos tareas precisadas, se orientan a resolver problemáticas específicas del área de la auditoría, llevándolos a reconocer los tipos de riesgos existentes tanto en los estados de cuenta como en los estados de pago de una empresa, siendo ambos evaluados por rúbricas.

Objetivo específico $\mathrm{N}^{\circ}$ : Evaluar la propuesta de estrategias activas de enseñanza-aprendizaje aplicada en las asignaturas del VIII nivel de la Carrera de Auditoría para el desarrollo de competencias transversales en sus alumnos. A continuación, se presentan los principales resultados, ordenados según las competencias transversales evaluadas en los alumnos y que han sido desarrolladas a través de la guía.

Trabajo en Equipo: Producto de una autoevaluación cuantitativa realizada, la mayoría de los 31 discentes, valorizan de manera óptima las cinco variables consideradas en esta competencia, destacándose un 58,60\% de ellos, que evalúan como totalmente logrado el haber asumido un rol 
dentro del grupo de manera clara y definida acorde a sus actitudes, y un 51,60\%, que evalúan de esta misma manera el respetar la asignación de responsables para el logro de cada actividad o tarea. Lo anterior se refleja mediante el siguiente gráfico.

\section{GRÁFICO N5: EVALUANDO MI DESARROLLO DE LA COMPETENCIA TRANSVERSAL DE TRABAJO EN EQUIPO.}

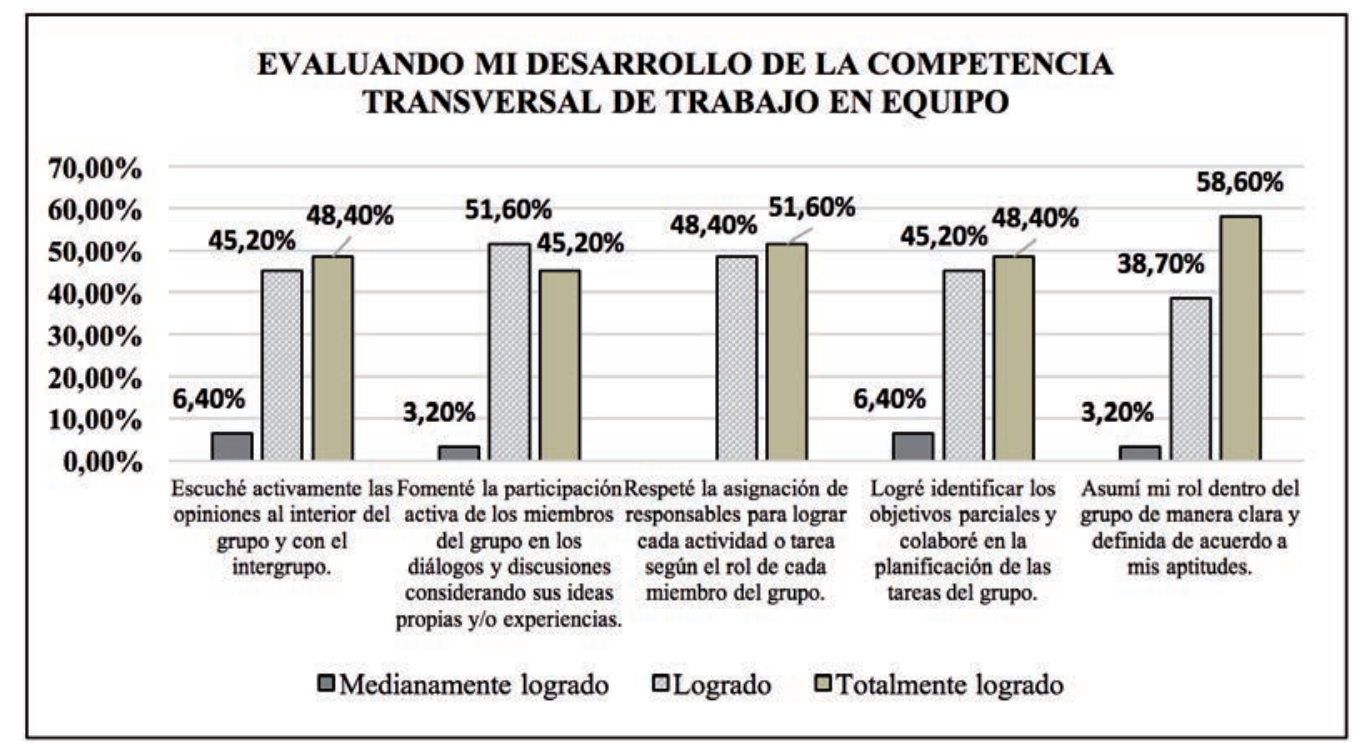

Fuente: Elaboración propia.

Por otra parte, respecto a una coevaluación cuantitativa concretada, si bien las cinco variables precisadas son evaluadas de manera óptima por la mayoría de los 31 alumnos, se destaca una evaluación de totalmente logrado por un $64.50 \%$ de ellos, ante el hecho que dentro del equipo los pares fomentaron la participación activa de sus miembros en los diálogos y discusiones, seguido de un $61,30 \%$, que evaluaron de esta misma manera, el hecho de que dentro de los equipos los compañeros identificaron los objetivos parciales y planificaron tareas en grupo.

Lo anterior puede ser graficado de la siguiente forma: 


\section{GRÁFICO N6: EVALUANDO EL DESARROLLO DE LA COMPETENCIA TRANSVERSAL DE TRABAJO EN EQUIPO EN MIS COMPAÑEROS.}

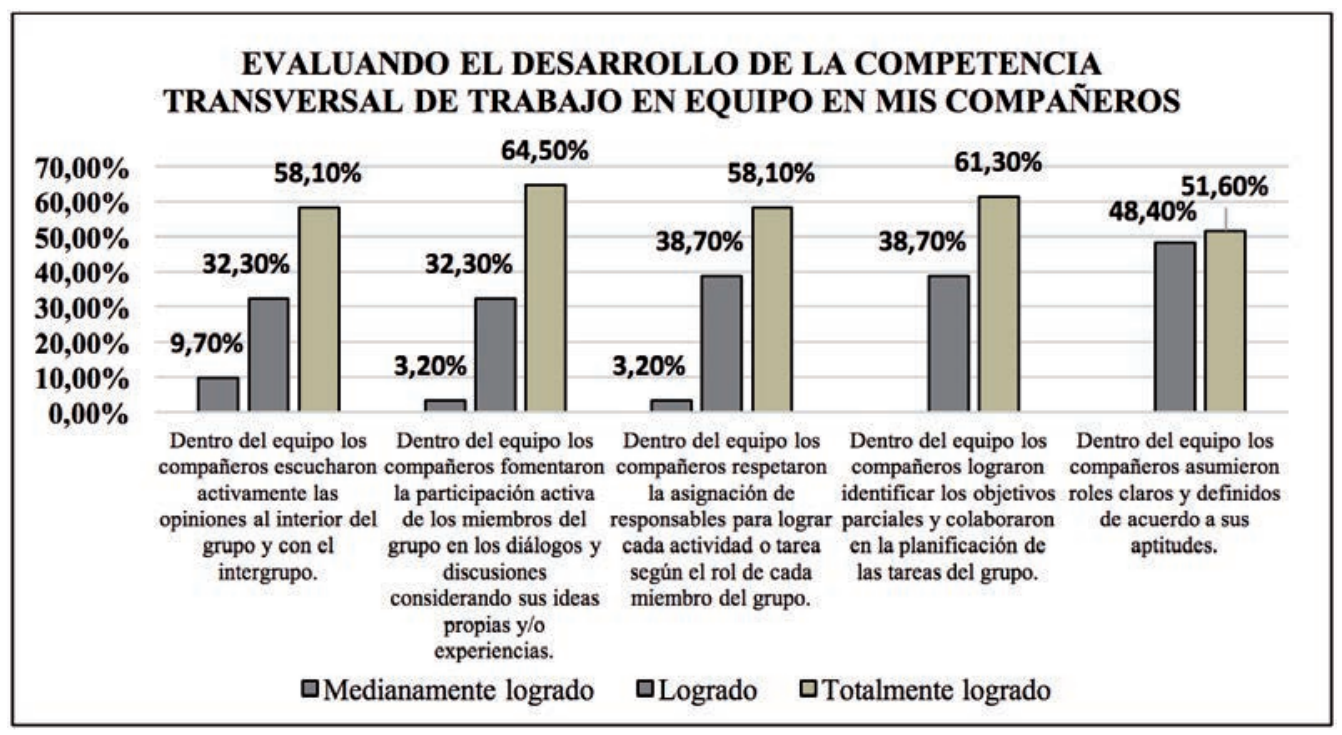

Fuente: Elaboración propia.

Por último, en lo que respecta a una heteroevaluación cuantitativa llevada a cabo, esta igual muestra una evaluación favorable en sus cinco variables consideradas, resaltando una evaluación de totalmente logrado por parte de los 3 académicos, al hecho de que sus alumnos fomentaron la participación activa dentro de los grupos, así como el respeto que se mostró por la asignación de responsables. Es así que los datos porcentuales entregados, quedan expresados de la siguiente:

\section{GRÁFICO N7: EVALUANDO EL DESARROLLO DE LA COMPETENCIA TRANSVERSAL} DE TRABAJO EN EQUIPO EN MIS ALUMNOS.

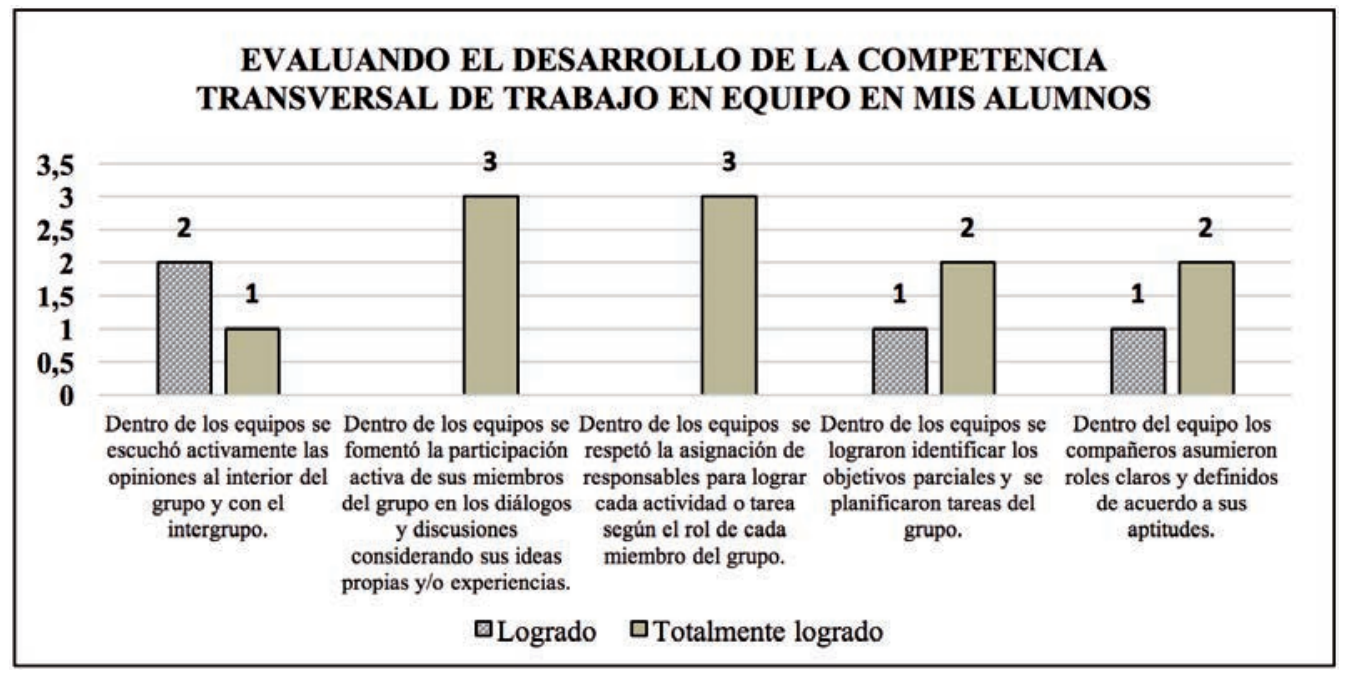

Fuente: Elaboración propia. 
Autonomía e Iniciativa Personal: Por una parte, la autoevaluación cuantitativa realizada, arroja una valoración positiva de sus cinco variables por la mayoría de los 31 estudiantes, destacándose un $77,40 \%$ de los discentes, que evalúan como totalmente logrado el aportar a un clima agradable al interior del grupo y un 54,80\%, que evalúan de esta misma manera, el proponer soluciones y/o generar alternativas a las diversas problemáticas suscitadas al interior del aula.

Lo anteriormente señalado, puede verse visualizado de la siguiente manera:

\section{GRÁFICO N8: EVALUANDO MI DESARROLLO DE LA COMPETENCIA TRANSVERSAL DE AUTONOMÍA E INICIATIVA PERSONAL.}

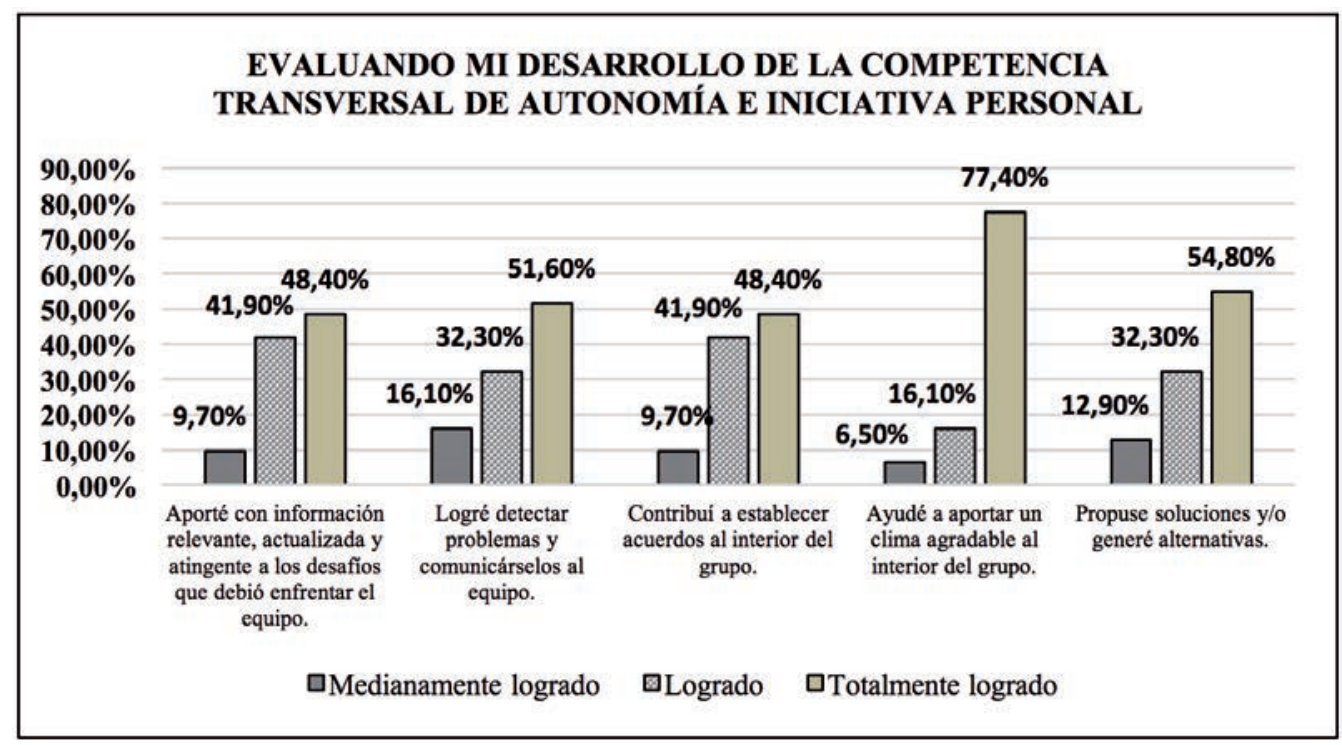

Fuente: Elaboración propia.

En lo que se refiere a la coevaluación cuantitativa concretada, los resultados muestran también una evaluación favorable en sus cinco variables por gran parte de los 31 alumnos.

En función de esto mismo, se resalta el hecho de que un $61,30 \%$ de los estudiantes, evalúan como totalmente logrado el que sus compañeros de equipo contribuyeron a establecer acuerdos al interior del grupo, y en un mismo porcentaje y con una misma evaluación, el hecho de que los compañeros de equipo contribuyeron a aportar un clima agradable en el grupo.

Lo anterior, puede ser graficado de la siguiente forma: 


\section{GRÁFICO N9: EVALUANDO EL DESARROLLO DE LA COMPETENCIA TRANSVERSAL DE AUTONOMÍA E INICITIVA PERSONAL EN MIS COMPAÑEROS.}

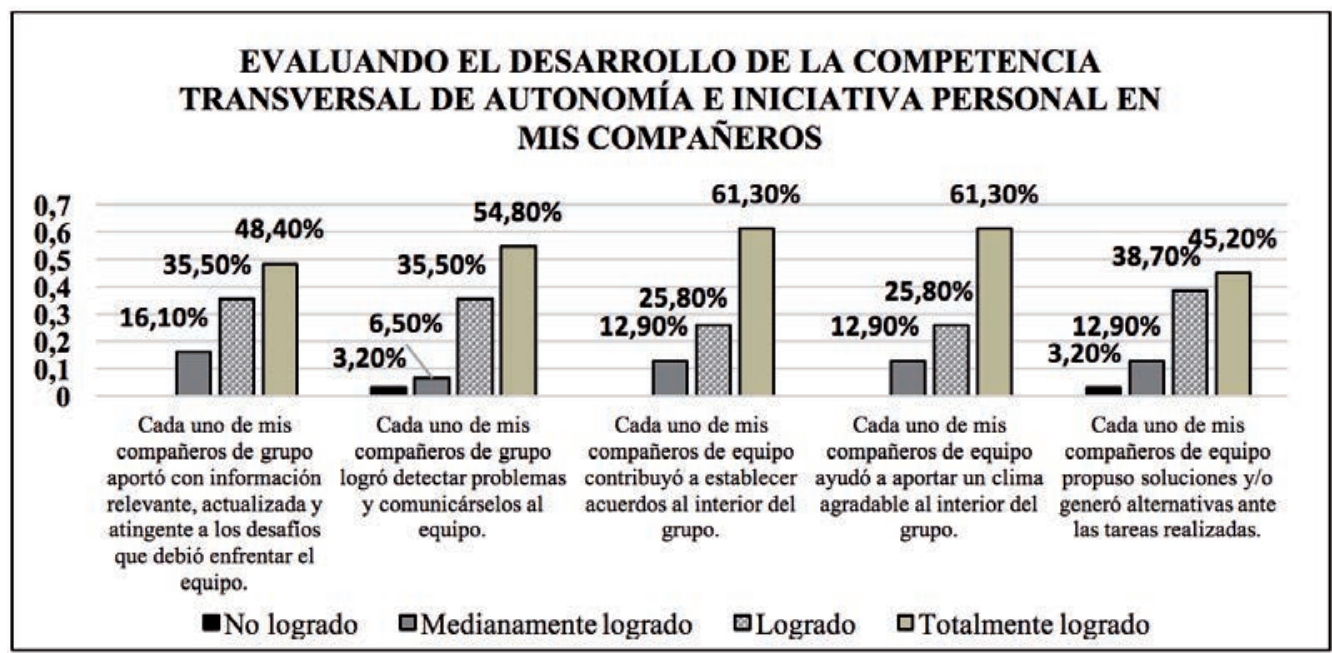

Fuente: Elaboración propia.

Por último, en función de la heteroevaluación cuantitativa llevada a cabo, es posible señalar, que sus cinco variables son evaluadas positivamente por los facultativos, destacándose el hecho de que los 3 docentes considerados, evalúan como totalmente logrado, el que los integrantes de los equipos contribuyeron a aportar a un clima agradable al interior del grupo, y bajo este mismo criterios y por los mismos 3 docentes, el hecho de que los integrantes de los equipos contribuyeron a establecer acuerdos. Lo anterior queda evidenciado de la siguiente manera:

GRÁFICO N¹0: EVALUANDO EL DESARROLLO DE LA COMPETENCIA TRANSVERSAL DE AUTONOMÍA E INICITIVA PERSONAL EN MIS ALUMNOS.

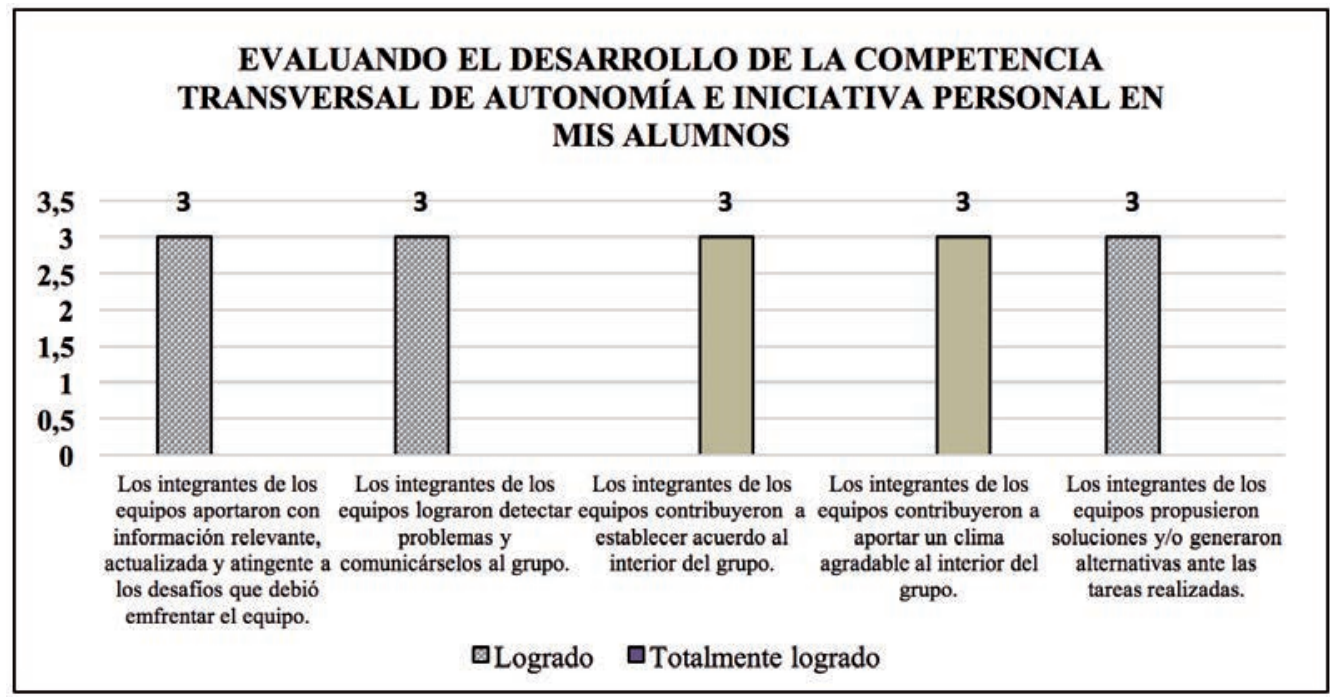

Fuente: Elaboración propia. 
Lectura Comprensiva: Ante una autoevaluación cuantitativa precisada, donde sus tres variables consideradas son evaluadas favorablemente por la mayoría de los 31 alumnos, se destaca que el $51,60 \%$ de los discentes, valoran como totalmente logrado el hecho de haber podido realizar ejercicios de comprensión lectora con los textos entregados, y en un mismo porcentaje y evaluándolo como logrado, el hecho de haber podido analizar y relacionar los textos leídos con la realidad de su contexto y cotidianidad. Lo anterior queda graficado de la siguiente forma:

\section{GRÁFICO N¹1: EVALUANDO MI DESARROLLO DE LA COMPETENCIA TRANSVERSAL DE LECTURA COMPRENSIVA.}

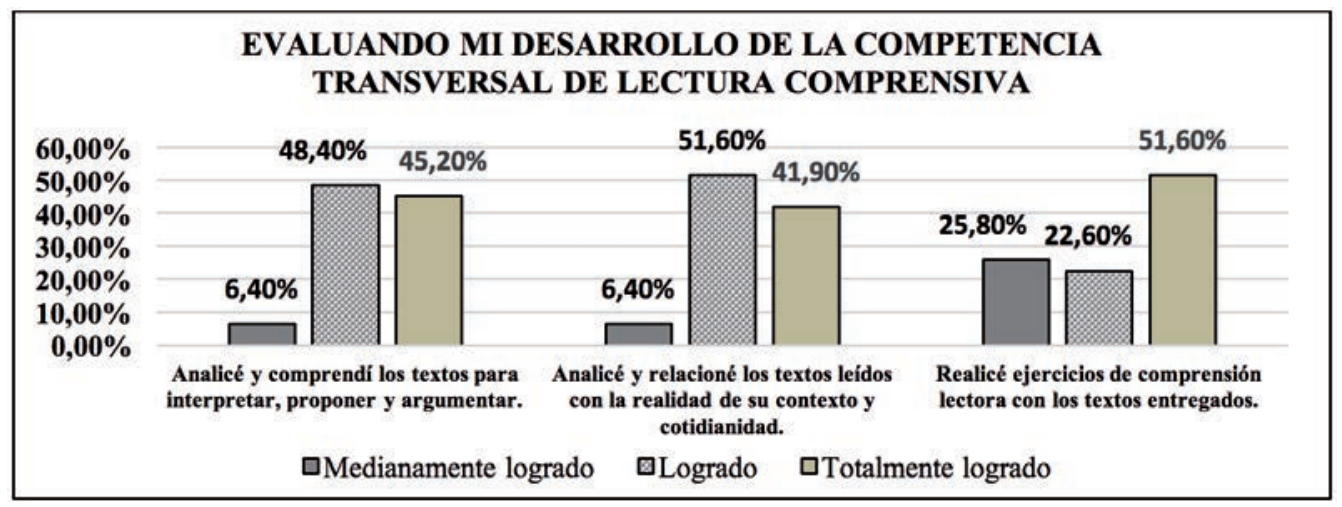

Fuente: Elaboración propia.

En lo que se refiere a la coevaluación cuantitativa realizada, si bien sus tres variables son evaluadas de manera positiva, si se aprecia un aumento de la evaluación en términos medios. A pesar de esto, se destaca un 61,30\% de los discentes, que evalúan como totalmente logrado el hecho de que sus pares hayan relacionado los textos leídos con la realidad del contexto y un 45,20\%, que valoran como logrado el hecho de que sus compañeros lograron analizar y comprender los textos para interpretar, proponer y argumentar. Lo anterior se grafica por medio del siguiente gráfico:

\section{GRÁFICO N¹2: EVALUANDO EL DESARROLLO DE LA COMPETENCIA TRANSVERSAL DE LECTURA COMPRENSIVA EN MIS COMPAÑEROS.}

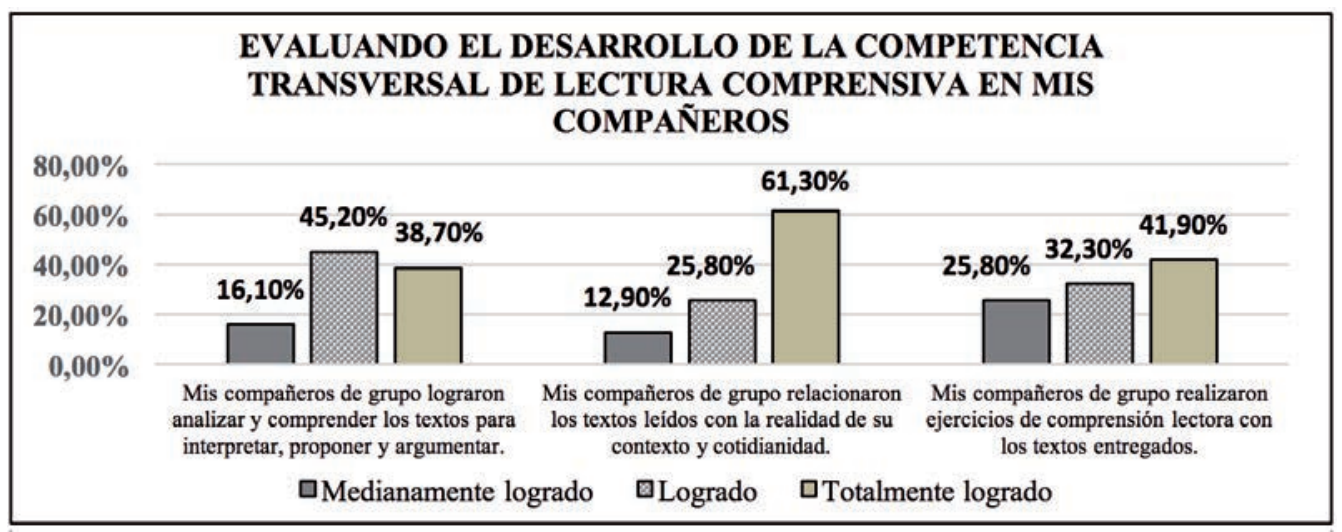

Fuente: Elaboración propia. 
Por último, respecto a la heteroevaluación cuantitativa realizada, si bien las tres variables consideradas son valoradas positivamente por la mayoría de los 3 docentes, al igual que en el caso anterior, se observa un aumento de la evaluación en términos medios en una de estas variables. A pesar de esto, se destaca el hecho de que de los 3 docentes considerados, 2 de ellos evalúan como logrado y 1 como totalmente logrado, el que los integrantes de los equipos hayan sido capaces de realizar los ejercicios de comprensión lectora con los textos entregados y el que los integrantes de los equipos hayan sido capaces de relacionar los textos leídos con la realidad de su contexto, lo cual se ve expresado de la siguiente manera:

GRÁFICO N¹3: EVALUANDO EL DESARROLLO DE LA COMPETENCIA TRANSVERSAL DE LECTURA COMPRENSIVA EN MIS ALUMNOS.

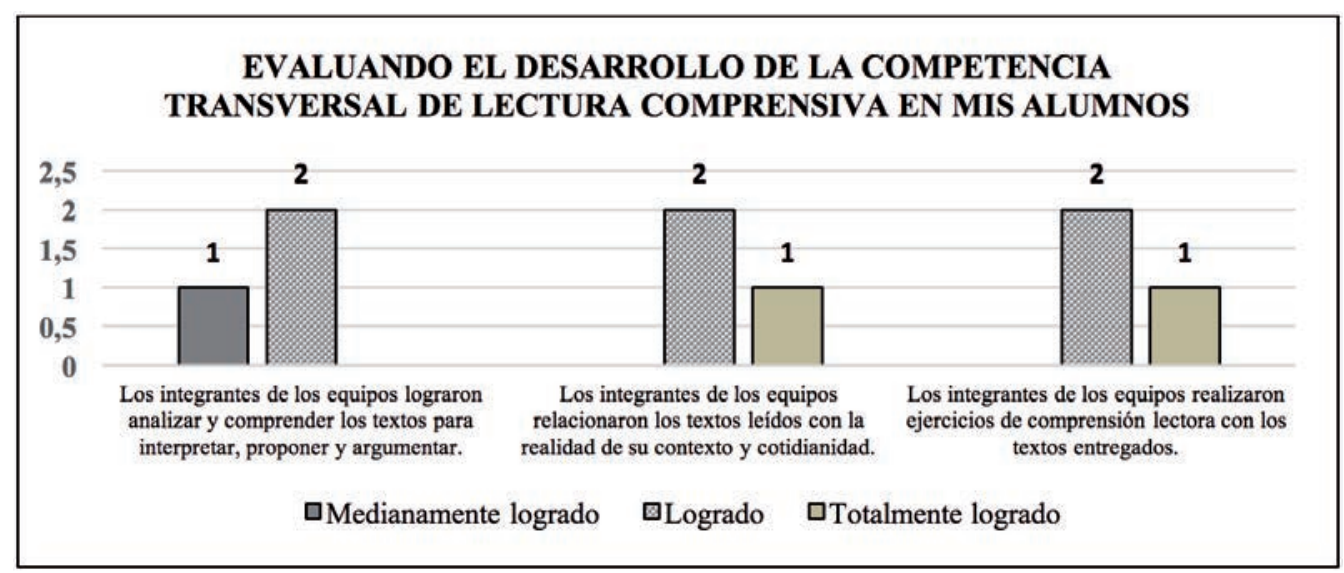

Fuente: Elaboración propia.

Razonamiento Lógico Matemático: Ante la autoevaluación realizada y considerando las cuatro variables precisadas, las cuales fueron evaluadas de manera óptima por la mayoría de los estudiantes, se destaca que un 38,70\% de los alumnos, evalúan como logrado la valoración del lenguaje contable como un instrumento útil para presentar, comunicar y resolver problemas de la vida diaria y un $35,50 \%$ de ellos, que evalúan como totalmente logrado, el haber evidenciado reflexibilidad al obtener las partes de una cuenta de contabilidad.

Esto se grafica de la siguiente manera: 


\section{GRÁFICO Nº14: EVALUANDO MÍ DESARROLLO DE LA COMPETENCIA TRANSVERSAL DE RAZONAMIENTO LÓGICO MATEMÁTICO.}

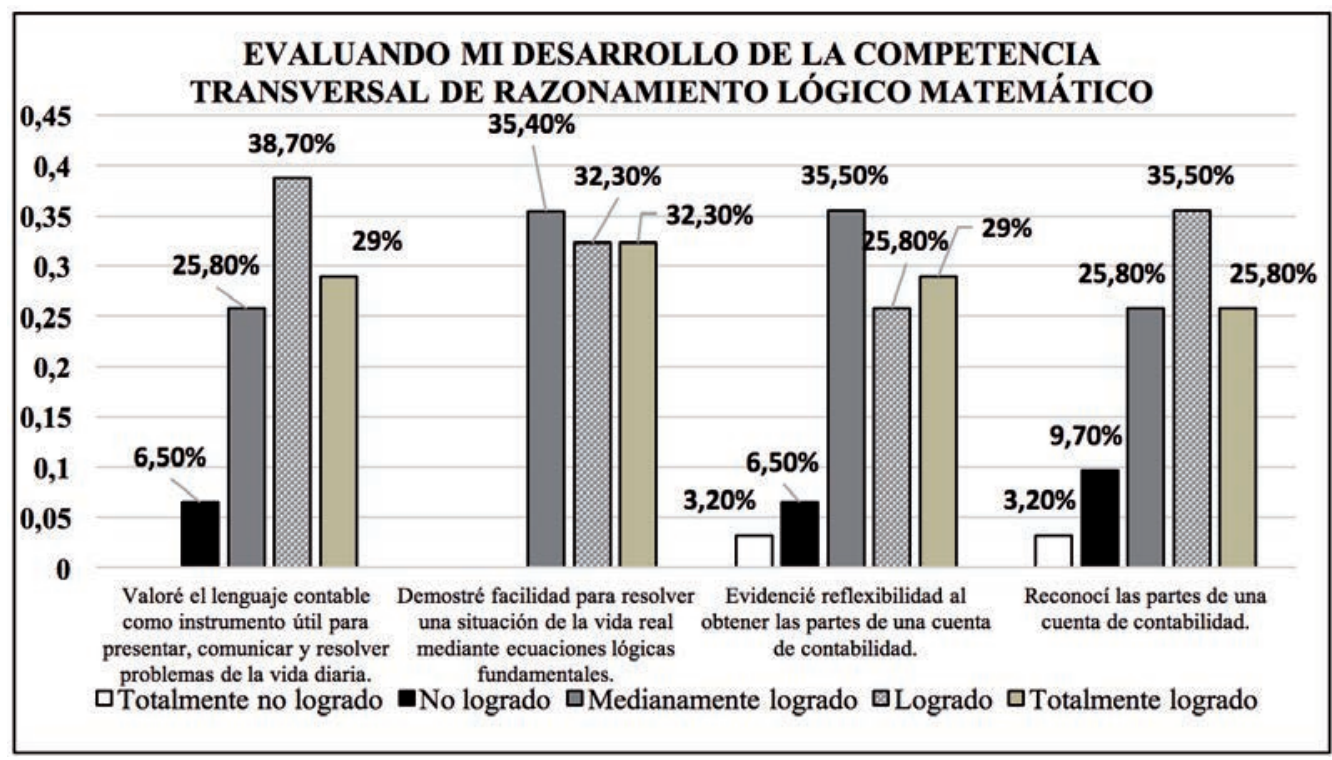

Fuente: Elaboración propia.

Entorno a la coevaluación, es posible argumentar, que sus cuatro variables son evaluadas de manera positiva, destacándose un 45,20\% de los estudiantes, que evalúan como logrado el hecho de que los compañeros de equipo valoraron el lenguaje contable como un instrumento útil para presentar, comunicar y resolver problemas, y un mismo porcentaje, que evalúan de la misma manera, el que los compañeros de grupo demostraron facilidad para resolver una situación de la vida real mediante ecuaciones. Esto se expresa por medio del siguiente gráfico: 


\section{GRÁFICO N¹5: EVALUANDO EL DESARROLLO DE LA COMPETENCIA TRANSVERSAL DE RAZONAMIENTO LÓGICO MATEMÁTICO EN MIS COMPAÑEROS.}

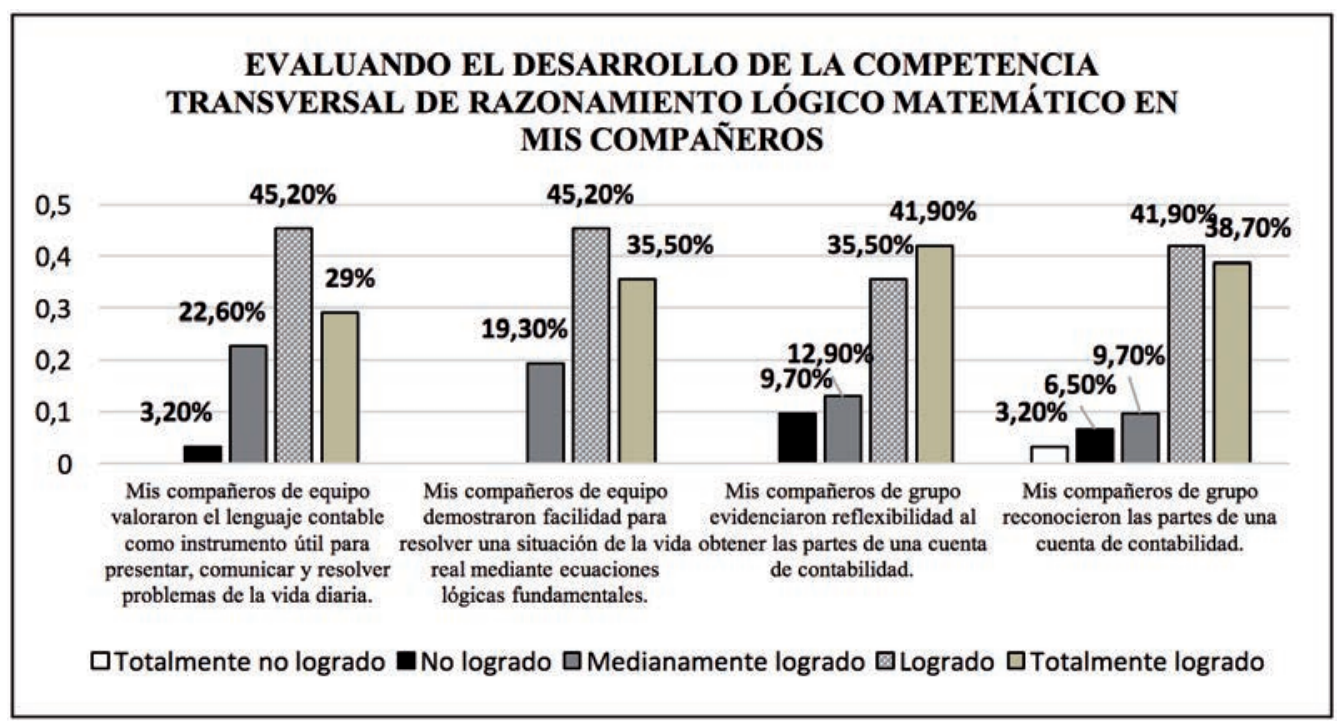

Fuente: Elaboración propia.

La heteroevaluación por otro lado, evidencia una evaluación positiva en tres de sus cuatro variables, donde hay una que presenta problemas en términos de valoración media a negativa. Es así, que por una parte, el hecho de que los integrantes de los equipos valoraran el lenguaje contable como un instrumento útil para presentar, comunicar y resolver problemas, el que estos evidenciaran reflexividad al obtener las partes de una cuenta de contabilidad y el que reconocieran las partes de una cuenta de contabilidad, son evaluadas favorablemente por los 2 docentes considerados, por otra, el que demostraran facilidad para resolver una situación de la vida real mediante ecuaciones lógicas fundamentales, es evaluada en términos medios y negativos por estos docentes. Lo anterior queda graficado de la siguiente forma: 


\section{GRÁFICO N¹6: EVALUANDO EL DESARROLLO DE LA COMPETENCIA TRANSVERSAL DE RAZONAMIENTO LÓGICO MATEMÁTICO EN MIS ALUMNOS.}

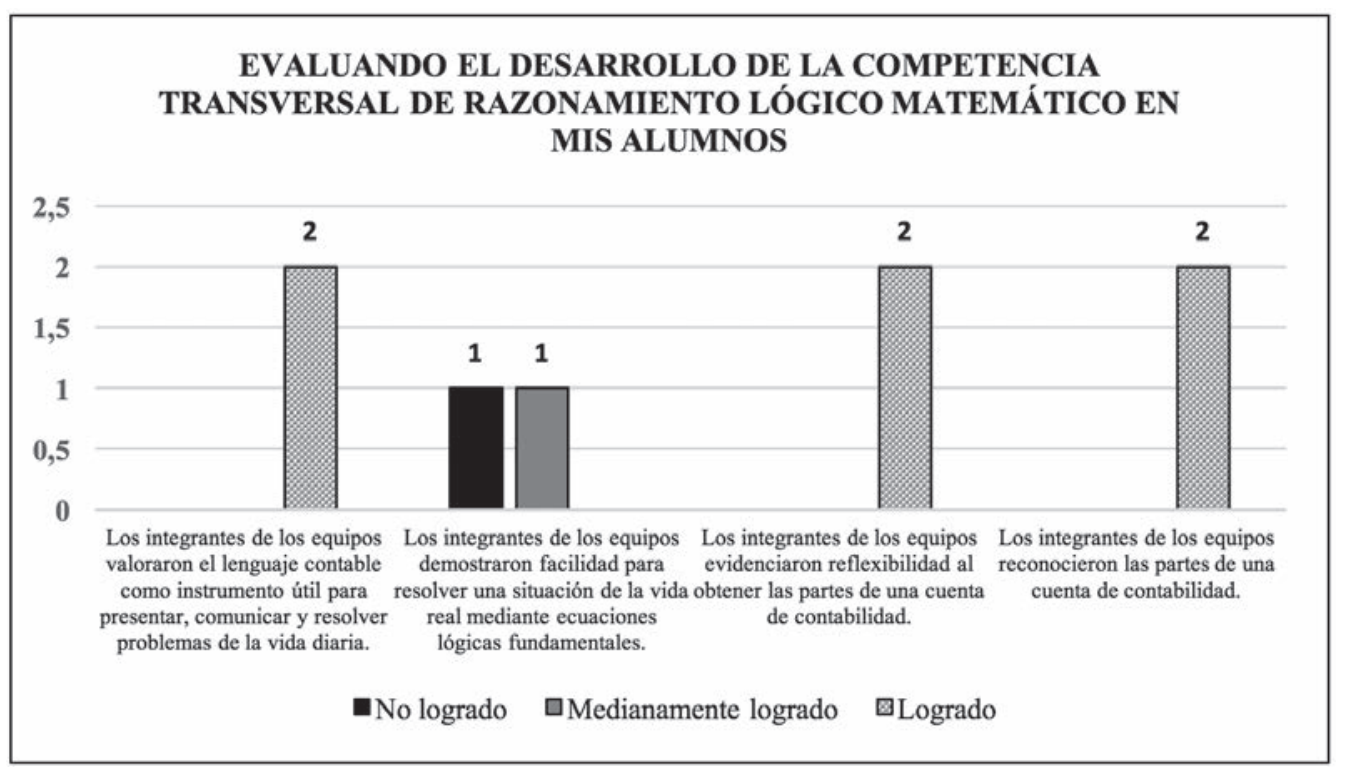

Fuente: Elaboración propia.

\section{DISCUSIÓN, CONCLUSIÓN}

Como se puede apreciar, a raíz de los resultados obtenidos tanto por medio de las entrevistas realizadas a la Directora de Escuela y a los docentes de último año, así como también por medio del focus groups llevado a cabo a los egresados de la Carrera de Auditoría que conforman el diagnóstico de este estudio, el modificar las estrategias de enseñanza-aprendizaje de los facultativos de esta carrera, se trasforma en una prioridad, pues estas estrategias al centrarse exclusivamente en los resultados y no en los procesos tal como lo señala Tobón (2007), se constituyen en el principal obstáculo para el desarrollo de competencias transversales, reproduciendo un rol pasivo en los estudiantes de VIII nivel, que los llevan finalmente a actuar como autómatas dentro del proceso.

Este hecho, lleva a que las competencias transversales declaradas en el perfil de egreso que ellos presentan un primer momento, sean evaluadas en términos medios y/o negativos respecto a su desarrollo.

Ejemplo de esto, recae en el hecho de que competencias como el Trabajo en Equipo evidencian una necesidad latente de potenciar un rol más activo de los discentes en el aula, pues comumentente estos se limitan a no expresar sus ideas propias y a no desarrollar la escucha activa a la hora de participar constantemente al interior de los grupos, o bien en el caso de la Autonomía e Iniciativa Personal, donde la falta de opinión propia a la hora de enfrentar los desafíos que se presentan al interior del grupo o el aportar con soluciones ante los problemas presentados, se enaltecen como algunos de los principales problemas que se dan en estos estudiantes, confirman- 
do de alguna manera, una imagen de autómatas del conocimiento, cuya labor dentro y fuera de las aulas de clases, esta solo dada por la asimilación de información, no generando finalmente una significación de los contenidos, por medio de una activación de los conocimientos previos que ellos ya poseen.

Mención aparte, merece la falta de desarrollo de competencias transversales de carácter más instrumental en los alumnos, como lo son la Lectura Comprensiva y el Razonamiento Lógico Matemático, lo cual al ser evaluados mayoritariamente en términos negativos, evidencian la falta de un mayor proceso de abstracción de conocimientos que les permita pasar del conocer y comprender, al analizar y aplicar.

Situaciones como estas, generan una falta de interpretación y entendimiento de la realidad bajo nuevas perspectivas, transformándolo en individuos monofocales y con puntos de vistas más cerrados y carentes de posturas críticas y analíticas, que es lo que la sociedad actual demanda. Hecho que es ratificado mediante el focus groups realizado a los egresados.

Es bajo esta premisa entonces, que se levanta una guía de estrategias activas de enseñanzaaprendizaje y se planifica su aplicación en los alumnos de último año, quienes son los que presentan preferentemente estos vacíos.

Una vez implementada la guía y como resultado de su concreción por medio de las asignaturas del VIII nivel, es posible constatar la importancia que las aplicación de estrategias activas generan en el proceso de enseñanza-aprendizaje de los estudiantes, llevándolos a un mayor desarrollo de las competencias transversales evaluadas, destacándose por sobre estas, competencias como el Trabajo en Equipo y la Autonomía e Iniciativa Personal. Pues por medio de un trabajo constante en el que son involucrados no solo los estudiantes, sino también los docentes que son capacitados en la implementación de la guía, se logra un mayor desarrollo de estas competencias.

En el caso del Trabajo en Equipo por ejemplo, resultados positivos frente a la evaluación de variables como la definición clara de roles al interior del grupo y el respeto en las funciones que deben cumplir cada uno de los integrantes, son criterios que son valorados tanto por los mismos estudiantes, como así también por sus docentes.

Entre las razones que avalan dichos porcentajes, estas pueden ser justificadas cualitativamente tanto por la visión panorámica y la conciencia colectiva que se genera por la participación activa de los estudiantes, así como también, por el asimilar la relevancia que adquiere la organización y planificación a la hora de poder actuar de manera cohesionada. Así lo señala uno de los alumnos: "Por medio de la actividad realizada, aprendí que trabajar en equipo no solo es distribuirse funciones, sino aprender a organizarse sobre la base de un trabajo tanto individual como grupal" (Alumno; Focus Groups N²).

Bajo esta misma línea, puede destacarse también, la evaluación óptima del desarrollo de la competencia de Autonomía e Iniciativa Personal, donde la totalidad de estudiantes y de los docentes, al evaluar de manera satisfactoria las variables asociadas a esta competencia, reflejan que los estudiantes han podido desarrollar una postura más propositiva a los problemas que se presentan al interior del grupo, transformándolos en actores activos dentro del proceso de enseñan- 
za-aprendizaje, donde no solo estos han comprendido la importancia de entregar sus opiniones y buscar soluciones ante las situaciones acontecidas, entregando así al grupo una perspectiva más amplia frente al problema, sino también, han significado la relevancia que adquiere el poder emitir opiniones con fundamento, sin dejar de lado el respeto a los acuerdos que se pueden lograr al interior del grupo.

Entre las razones cualitativas que avalan lo anterior, puede destacarse, el hecho de que los estudiantes han comprendido la importancia que adquiere tanto para sí mismo como para el grupo en general, que el ser parte de un todo, involucra también una responsabilidad personal a la hora de asegurar el éxito de una tarea, lo cual va en directo beneficio tanto individual como colectivo.

Tal como lo señala uno de los estudiantes: "He comprendido que el ser parte activa dentro de una comunidad, no solo me ayuda a poner a prueba mis conocimientos, sino también ayuda a los demás, en cuanto a lo que yo puedo aportar, no esperando que las cosas me lleguen de la nada, sino yo buscando respuestas en la medida en que estas no se encuentren" (Alumno; Focus Groups N³).

Por otra parte, en el caso de las competencias de Lectura Comprensiva y de Razonamiento Lógico Matemático, si bien igualmente puede apreciarse una tendencia positiva frente a la evaluación del desarrollo de estas competencias, no puede obviarse, que son estas las que arrojan mayores resultados en términos medios.

Al preguntarse por las razones de esta evaluación, en el caso de la Lectura comprensiva por ejemplo, si bien aspectos como el poder argumentar frente a la información entregada y el poder relacionar los textos con la realidad, son aspectos destacados como positivos, la necesidad de una mayor ejercitación comprensiva con los textos entregados, es un punto que debe ser desarrollado. Lo anterior refleja una realidad que es importante de resaltar, y esta guarda relación con que no solo basta con llevar al estudiante a trabajar la comprensión de textos y documentos, sino que debe inculcárseles un hábito de lectura, lo cual es difícil que los alumnos logren desarrollar de un momento a otro.

Es así, que si bien tanto los estudiantes como docentes, evalúan de manera positiva el hecho de que los discentes han logrado avanzar en la comprensión y argumentación de los textos leídos, lo cual les ha permitido explicar la realidad, el problema aunque ha mejorado, sigue recayendo en el hecho de la falta de hábitos de lectura, lo cual es reafirmado a la hora de que son ellos mismos, los que evalúan de manera más crítica, el poder ejercitar constantemente la Lectura Comprensiva.

Lo anterior, puede verse reflejado también, en el comentario del siguiente estudiante: "Creo que los ejercicios de comprensión lectora entregados en clases, me ayudaron a reflexionar mejor y a tener una postura más crítica, aunque el problema recae en que es un hábito que debe hacerse permanente, y si no me lo dicen que lo haga, aún me cuesta hacerlo"' (Focus Groups N4).

Finalmente, en el caso del Razonamiento Lógico Matemático, si bien a nivel general se aprecia una tendencia positiva, ocurre algo similar respecto a la evaluación anterior, destacándose incluso una evaluación negativa por parte de uno de los docentes. 
Es así, que si bien en esta competencia, aspectos que resaltan, son la valoración que los estudiantes le otorgan al lenguaje contable como un instrumento útil en la resolución de problemas, y la reflexibilidad desarrollada a la hora de comprender el lenguaje matemático, aún existe cierta dificultad a la hora de explicar la realidad bajo este lenguaje.

Lo anterior refleja así, la necesidad de una mayor transferencia teórico-práctica, lo cual permita plasmar los conocimientos adquiridos en función de la realidad y cotidianidad diaria.

Esto puede ser plasmado por medio del siguiente comentario de uno de los docentes: “Siento que los alumnos, han mejorado su lógica matemática, pueden desarrollar ejercicios y problemas que antes no podían, pero aún les cuesta llevarlo a hechos concretos, y aplicarlo en situaciones reales que sean más complejas" (Académico N³)

Como se puede apreciar, en el caso de estas dos últimas competencias, si bien su desarrollo no deja de ser positivo, hay aspectos que deben ser mejorados, los cuales al preguntarse por las razones que llevan a que estas no lograrán tan óptimos resultados como las dos primeras, la respuesta viene dada por lo que nos señala Tobón (2007) al hacer referencia que estas competencias al ser de tipo instrumental y requerir un mayor desarrollo cognitivo, necesitan de un mayor tiempo de entrenamiento, donde no solo la voluntad es necesaria, sino también el perfeccionamiento constante.

A modo de concluir este proyecto, es posible señalar, que sin duda las estrategias activas de enseñanza-aprendizaje constituyen un camino adecuado a la hora de potenciar el desarrollo de competencias transversales, pues en ellas se encuentra la génesis del aprendizaje, permitiendo al alumno, durante décadas ignorado, ser participe en la construcción de sus conocimientos.

El proyecto llevado a cabo, no es el término de una labor, sino el comienzo de otra, que se asienta en lograr que toda una carrera en sus diferentes niveles pueda contar con una guía de estrategias activas con el fin de potenciar el desarrollo de estas competencias, considerando desde sus niveles más básicos hasta su último nivel, entendiendo que para el éxito de la misma, se necesita atravesar todo el proceso de formación académica, entregando a la sociedad, individuos claramente empoderados y preparados respecto a una serie de atributos de corte personal, sistémicos e instrumentales, que le permitan integrarse a la sociedad como agentes críticos y transformadores del medio. De esta manera, el seguir potenciando este cuerpo de competencias es fundamental, de allí que se propongan sugerencias como: 1.- Incorporar de manera previamente planificada, actividades que sin dejar de potenciar competencias técnicas potencien las competencias transversales, 2.- la necesidad de un reforzamiento a los alumnos de la Carrera de Auditoría sobre la importancia laboral y personal que tienen estas competencias, 3.- tomar esta guía como base para expandir sus beneficios a la carrera, 4.- capacitar a todos los docentes de la carrera, utilizando las Tics que posee la universidad, y 5.- potenciar el trabajo colegiado entre diversas asignaturas. 


\section{REFERENCIAS BIBLIOGRÁFICAS}

Alles M. (2005). El Desempeño por Competencias: Evaluación en 360. Buenos Aires, Argentina: Granicia.

Díaz-Barriga A. y Hernández G. (2010). Estrategias docentes para un aprendizaje significativo. Una interpretación constructivista. México DF, México: Mc Graw-Hill.

Fernández A. (2006). Metodologías Activas para la Formación de Competencias. Educación siglo XXI, Vol. N¹4, pp. 45-61.

Hernández R. Fernández C \& Baptista L. (2014). Metodología de la investigación científica- México DF, México: McGraw-Hill.

Serna H. (2013). Metodologías activas del aprendizaje. Medellín, Colombia: Fondo editorial Cátedra María Cano.

Tobón S. (2007). El enfoque complejo de las competencias y el diseño curricular por ciclos propedéuticos. Revista de Acción Pedagógica, Vol. N¹6, pp. 1-15.

Tuning. (2007). Reflexiones y perspectivas de la educación superior en América Latina (Informe Final Proyecto Tuning América Latina 2004-2007). Bilbao, España: Publicaciones Universidad de Deusto. 